\title{
The Nusantara Characters in Overcoming Negative Behaviors
}

\author{
Muhammad Kashai Ramdhani Pelupessy
}

Dosen Psikologi IAIN Ambon. Jl. Dr. H. Tarmizi Taher, Kebun Cengkeh, Batu Merah, Sirimau, Kota Ambon, Maluku.

Email: mkrpelupessy@iainambon.ac.id

\begin{abstract}
Understanding Nusantara character is important to overcome negative behaviors that often occur in the hearts of community. This study attempts to explore how Nusantara character is able to overcome negative behaviors. This study is literature in nature using several Indonesian journals of psychology. The results of this study indicate that the characters are developed from subjective happiness, motivation of achievement, and tolerance. These three characters have potentials to overcome negative behaviors. The author suggests that Indonesian researchers in psychology need to meticulously investigate cultural values in certain communities and the construction of Nusantara characters.
\end{abstract}

Keywords: personality archipelago, negative behavior

\section{Karakteristik Kepribadian Nusantara dan Relevansinya Mengatasi Perilaku Negatif}

\begin{abstract}
Abstrak
Menelurusi karakteristik kepribadian nusantara ini penting dilakukan untuk mengatasi perilaku negatif yang kerap muncul di tengah-tengah masyarakat. Tujuan penelitian ini berusaha menunjukkan karakteristik kepribadian nusantara, sekaligus menjadi solusi alternatif mengatasi perilaku negatif. Penelusuran ini menggunakan studi literatur, diambil dari jurnal-jurnal psikologi Indonesia. Hasil penelusuran menunjukkan bahwa karakteristik kepribadian nusantara ialah kebahagiaan subjektif, motivasi berprestasi, dan toleransi. Karakteristik ini dapat menjadi solusi alternatif mengatasi perilaku negatif. Jadi, kesimpulannya ialah karakteristik kepribadian nusantara meliputi kebahagiaan, motivasi, dan toleransi, yang hal ini dapat berkontribusi mengatasi perilaku negatif. Meskipun demikian, penelusuran ini memiliki keterbatasan yakni masih minimnya sumber-sumber penelitian psikologi nusantara, ke depan para peneliti psikologi Indonesia perlu menggali nilai-nilai budaya dalam masyarakat tertentu dan mengkonstruknya menjadi kepribadian nusantara.
\end{abstract}

Kata Kunci: kepribadian nusantara, perilaku negatif

* Naskah diterima Agustus 2021, direvisi Oktober 2021, dan disetujui untuk diterbitkan November 2021 


\section{A. Pendahuluan}

Tantangan terbesar para ilmuwan psikologi Indonesia sekarang ini ialah menelusuri kepribadian nusantara. Upaya penelurusan sudah dilakukan (misalnya., Prihartanti, 1999; Prihartanti et al., 2003; Prawitasari, 2006; Ralahallo, 2009; Trimulyaningsih, 2017), semua upaya ini untuk mengetahui kepribadian "khas" nusantara dan relevansinya mengatasi masalah perilaku negatif yang kerap muncul di tengah-tengah masyarakat Indonesia.

Belakangan, upaya itu terpolarisasi ke dalam dua spektrum pandangan yang berbeda. Pertama, pandangan psikologi terapan, yakni para ahli psikologi meneliti kepribadian nusantara untuk tujuan praktis sehingga tampak kepribadian itu bersifat etik atau berlaku universal (Widyarini, 2008; Prawitasari, 2006). Kedua, pandangan psikologi murni, yakni upaya meneliti kepribadian nusantara untuk tujuan teoritis sehingga tampak kepribadian bersifat emik atau hanya dimiliki individu dalam komunitas masyarakat tertentu (Widyarini, 2008; Prihartanti, 1999). Berangkat dari dua pandangan yang berbeda itu, sebetulnya memiliki tujuan yang sama yakni upaya mengatasi masalah perilaku negatif yang kerap muncul di tengah-tengah masyarakat.

Masalah perilaku negatif yang kerap muncul belakangan ini ialah kekerasan atau konflik lintas etnis dan agama (Subandi, 1995; Komnas HAM, 2019), perilaku korupsi (Susanto, 2009; Muluk, 2008; Winurini, 2017; ICW, 2020), bahkan mengerucut pada persoalan disintegrasi bangsa (Sairin, 2000; Kusumawardani \& Faturochman, 2004; Sobandi, 2011; Nainggolan, 2014). Kekerasan lintas etnis dan agama, misalnya, berdasarkan laporan survei Komisi Nasional Hak Asasi Manusia (Komnas HAM) Republik Indonesia menunjukkan bahwa kasus kekerasan mengalami peningkatan akhir-akhir ini (Komnas HAM, 2019). Fenomena kekerasan disebabkan banyak faktor, salah-satu di antaranya ialah kemiskinan dan ketidakadilan sosial (Caruso \& Schneider, 2011; Khattab et al., 2018), fundamentalisme agama (Ellis, 2017), dan prasangka sosial (Rowatt \& Al-Kire,
2021). Kekerasan sangat berdampak pada suasana psikologis individu yakni stres (Nyarko et al., 2020; Binder et al., 2020) dan perasaan traumatik (Steel et al., 2009). Uniknya, belakangan ini konsentrasi penelitian psikologi cukup besar membahas perilaku negatif dibanding menonjolkan aspek positif dari perilaku manusia (Sumanto, 2006). Padahal, ada yang lebih penting selain meneliti perilaku negatif, yakni menelusuri perilaku positif yang tersimpan di balik nilai-nilai setiap budaya di berbagai daerah (Akhtar, 2018).

Pertanyaannya ialah apakah fenomena perilaku negatif seperti kekerasan murni merupakan kepribadian nusantara? Pertanyaan ini butuh jawaban serius dan mendalam, karena perilaku negatif tampak bersifat universal. Bahkan karena universalitas itu, salah-satu wartawan senior Mochtar Lubis memasukkan karakter negatif orang Indonesia di antaranya ialah hipokrit dan percaya takhayul (Lubis, 2012). Pendapat ini masih bersifat common sense karena belum dibuktikan secara ilmiah. Meskipun demikian, asumsi itu memancing penelitian lebih lanjut terkait upaya mencari solusi untuk mengatasi perilaku negatif di tengah-tengah masyarakat.

Langkah paling dekat sekarang ini ialah menelusuri: Apakah ada kepribadian nusantara? Apa saja karakteristik kepribadian nusantara berdasarkan hasilhasil penelitian para ahli psikologi Indonesia? Apakah karakteristik kepribadian nusantara dapat mengatasi perilaku negatif? Tujuan penelusuran ini ialah disamping memberi solusi alternatif mengatasi perilaku negatif, juga untuk merumuskan dan menunjukkan karakteristik kepribadian nusantara kepada masyarakat ilmiah, pengambil kebijakan, dan masyarakat luas.

\section{B. Metode Penelitian}

Jenis penelitian ini ialah kualitatif dengan pendekatan studi literatur. Studi literatur yang digunakan dalam penelitian ini mengacu pada pendapat Fink (2020) bahwa sejumlah literatur yang dikaji dalam penelitian ini bersumber dari database jurnal 
online. Oleh karena itu, literatur yang dikaji dalam penelitian ini bersumber dari jurnaljurnal terakreditasi Sinta, terindeks Portal Garuda, dan sejumlah artikel ilmiah dalam bentuk Prosiding yang telah dipresentasikan para ahli psikologi Indonesia di setiap konferensi. Literatur ilmiah yang diambil ialah dari jurnal-jurnal ilmiah yang diteliti para ahli psikologi Indonesia.

Studi literatur ini untuk menjawab pertanyaan penelitian: "Apakah ada kepribadian nusantara? Apa saja karakteristik kepribadian nusantara berdasarkan hasil-hasil penelitian para ahli psikologi Indonesia? Apakah karakteristik kepribadian nusantara dapat mengatasi perilaku negatif?". Untuk menjawab pertanyaan tersebut, maka studi literatur ini dilakukan melalui beberapa tahapan yakni tahap 1 (perencanaan), tahap 2 (peninjauan), dan tahap 3 (pelaporan), hal ini sebagaimana dilakukan oleh Li et al (2021).

Pada tahap 1 (perencanaan) ialah untuk menjawab pertanyaan penelitian di atas. Dalam proses menjawab pertanyaan penelitian tersebut, maka ditelusuri sejumlah artikel yang relevan dengan kata kunci "karakteristik kepribadian nusantara", "kepribadian orang Jawa", "kepribadian orang Batak", "kepribadian orang Maluku", "perilaku nusantara", dan sejenisnya. Kata kunci ini ditemukan pada sejumlah website jurnal psikologi di Indonesia, tanpa mengecualikan sejumlah website jurnal luar negeri seperti ScienceDirect dan Tandfonline.

Pada tahap 2 (peninjauan) ialah untuk melakukan review terhadap sejumlah jurnal psikologi yang relevan menjawab pertanyaan penelitian. Review ini dilakukan untuk mencari tahu karakteristik kepribadian yang dimiliki masing-masing daerah di Indonesia berdasarkan studi-studi para ahli psikologi Indonesia. Tahap 3 (pelaporan) ialah melaporkan hasil review dalam bentuk pembahasan untuk menjawab pertanyaan penelitian di atas.

\section{Hasil dan Pembahasan}

Istilah "nusantara" pertama kali muncul dalam sumpah palapa yang diucapkan adipatih Majapahit Gajda Mada. Dalam sumpahnya itu, istilah nusantara digaungkan yang berarti sejumlah pulau mencakup Jawa, Seram (Maluku), Palembang (Sumatera), Dompu (Nusa Tenggara Timur), Bali, dan lainnya yang sekarang dikenal sebagai Indonesia. Hal ini sesuai dengan pengertian nusantara yang terdiri dari dua suku kata yakni nusa (pulau) dan antara (jarak), kedua suku kata itu berasal dari bahasa sansekerta. Artinya, nusantara berarti gugusan pulau-pulau yang terpisah oleh jarak lautan. Dalam bahasa Inggris, istilah nusantara disebut archipelago yang berarti pulau-pulau yang saling terpisah namun disatukan oleh lautan (Latif, 2019).

Sebagaimana istilah nusantara yang berarti gugusan pulau-pulau, dan setiap pulau menyimpan nilai-nilai kearifan lokal (budaya, adat istiadat) yang khas dan unik, maka tidak menutup kemungkinan bahwa kepribadian masing-masing masyarakat di berbagai daerah menjadi sangat beragam (individual differences). Hal ini tampak dari ekspresi kepribadian masyarakat, misalnya orang Maluku berbeda dengan orang Jawa, juga berbeda dari orang Batak. Penyebabnya ialah karena nilai-nilai kearifan lokal dari masing-masing daerah sangat kuat membentuk kepribadian setiap individu di dalam masyarakat. Meskipun demikian, perbedaan ini telah menjadi keniscayaan, bahkan karena perbedaan itu maka masyarakat nusantara bisa bertahan dan beradaptasi dengan segala perubahan yang terjadi begitu cepat sekarang ini. Hal ini sebagaimana sifat lautan yang menyatukan nusantara ialah mampu menerima berbagai corak perubahan dan perbedaan yang bernilai positif dan membersihkan segala hal yang berbau negatif (Latif, 2019).

Kekuatan lingkungan (nilai-nilai kearifan lokal) memang sangat kuat membentuk kepribadian individu. Psikolog terkenal Kurt Lewin mengatakan bahwa dinamika kepribadian individu sangat kuat dibentuk oleh faktor lingkungan dan peran person lainnya (Soeparno \& Sandra, 2011). Lewin menguraikan pendapatnya itu dalam 
rumus psikologi yakni $B=f(P, E)$ yang berarti $B$ (behavior), $f$ (factor), $P$ (person), dan $E$ (environment). Artinya, dinamika kepribadian individu sangat kuat ditentukan oleh faktor person (orang-orang di sekitar individu) dan lingkungan (nilainilai kearfian lokal). Selain Lewin, psikolog terkenal lainnya ialah Urie Bronfenbrenner juga mengatakan bahwa kepribadian individu sangat kuat dipengaruhi lingkungan (Andayani, 2004). Ulasan Bronfenbrenner sebagaimana pada gambar 1 di bawah ini.

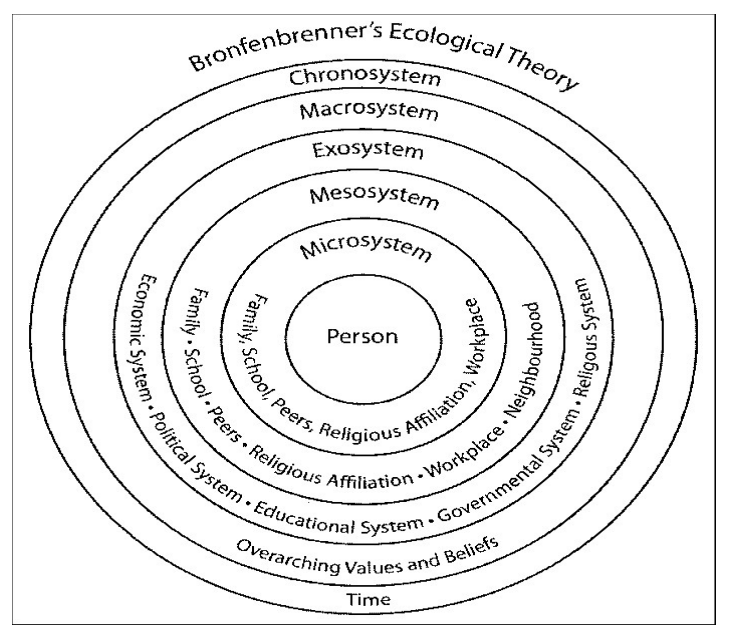

Gambar 1. Teori Ekologi Bronfenbrenner diambil dari Stanger (2011)

Brofenbrenner mengatakan bahwa kepribadian setiap individu berkembang seiring dengan dipengaruhi sistem lingkungan tempat tinggal individu. Karena individu itu mengalami perkembangan psikologis seiring pertumbuhan usia, maka lingkungan yang dimasuki individu pun menjadi sangat dinamis dan punya kekuatan membentuk kepribadiannya (Andayani, 2004). Jika semua sistem lingkungan yang dilalui individu digabungkan menjadi satu, maka akan membentuk environmental press yang sangat kuat menentukan kompleksitas kepribadian individu di masa mendatang (Andayani, 2004). Misalnya, mengacu pada gambar 1 di atas bahwa individu berkembang memasuki sistem lingkungan mikro, meso, ekso, dan makro. Sistem lingkungan mikro ialah mencakup inti keluarga, sekolah, dan teman sebaya individu. Sistem lingkungan meso ialah mencakup warga kampung dan masyarakat sekitarnya. Sistem lingkungan ekso ialah suatu lingkungan di luar individu tapi sangat kuat mempengaruhi kepribadian individu. Misalnya, lingkungan tempat kerja orang tua. Terakhir, sistem lingkungan makro ialah suatu sistem yang sangat besar seperti kehidupan ideologi suatu negara atau nilai-nilai universal. Setiap sistem lingkungan tersebut sangat kuat membentuk kepribadian individu. Oleh karena itu, dapat dikatakan bahwa pengaruh lingkungan (kearifan lokal) dari masing-masing daerah (pulau; nusantara) sangat kuat membentuk kepribadian individu.

Berdasarkan ulasan tersebut, maka yang dimaksud dengan kepribadian nusantara ialah pengaruh nilai-nilai kearifan lokal dari setiap daerah di nusantara (pulau-pulau) sangat kuat membentuk kepribadian individu. Inilah yang kami sebut sebagai "kepribadian nusantara". Selanjutnya, pengaruh nilai-nilai kearifan lokal (lingkungan) dari setiap daerah (di nusantara) membentuk kepribadian individu diulas sebagai berikut.

\section{Konsep Kepribadian Suryomentaraman}

Hasil-hasil penelitian psikologi Indonesia yang concern mengulas kepribadian nusantara ialah mengacu pada konsep kepribadian yang dirumuskan Suryomentaraman (Prihartanti, 1999; Prawitasari, 2006; Widyarini, 2008; Sumanto, 2011; Trimulyaningsih, 2017; Afif, 2020). Suryomentaram (Widyarini, 2008) mengulas dinamika kepribadian di dalamnya terdiri dari empat dimensi yakni fungsi fisikal (dimensi I), emosional (dimensi II), intelektual (dimensi III), dan intuisional (dimensi IV). Kepribadian setiap individu muncul dari akumulasi dimensi I sampai IV tersebut.

Widyarini (2008) dan Afif (2020) mengulas dimensi I adalah proses individu mencatat segala sesuatu yang berhubungan dengan dirinya. Catatan-catatan ini kemudian masuk ke dimensi II menjadi catatan pengalaman hidup, dapat menyenangkan atau tidak menyenangkan. 
Dimensi III bersifat rasional (intelektual), Suryomentaraman menyebutnya si tukang pikir. Antara dimensi III ke dimensi IV terdapat "jalan simpang tiga", antara mengikuti catatan-catatan pengalaman hidup ataukah bertindak rasional-reflektif. Widyarini (2008) mengatakan jika individu mengikuti catatan pengalaman hidup, maka ia akan menuju rasa kradamangsa penuh sifat egoistik. Namun, jika individu tidak mengikuti catatan pengalaman hidup maka ia akan mengarah pada manusia tanpa ciri yakni kesadaran altruistik dan kebahagaiaan subjektif (Widyarini, 2008; Akhtar, 2018).

Contoh konkrit dinamika kepribadian yang dirumuskan Suryomentaraman ialah seperti kita sering merasa kecewa atau marah ketika catatan-catatan pengalaman hidup (rasa kradamangsa) kita diganggu/ tidak terealisasi oleh situasi atau pihak lain (Afif, 2020). Catatan pengalaman hidup (rasa kradamangsa) ini, misalnya, rasa ingin dihormati orang lain, ketika rasa ini tidak terwujud maka kita cenderung kecewa atau marah kepada orang lain tersebut. Penyebabnya ialah karena setiap individu memiliki catatan pengalaman hidupnya sendiri-sendiri. Oleh karena itu, kekecawaan yang timbul karena tidak terpenuhinya rasa kradamangsa karena terbentur dengan catatan-catatan pengalaman hidup orang lain, maka Widyarini (2008) mengatakan bahwa benturan antara rasa kita dengan rasa kradamangsa pihak lain ini akan membuahkan perselisihan tanpa henti.

Solusi untuk mengatasi perselisihan itu ialah setiap individu harus mencoba melepaskan rasa kradamangsa yang cenderung membelenggu jiwa menuju kebahagiaan sejati. Suryomentaraman dalam ulasan Afif (2020) menawarkan olah rasa (mawas diri) sebagai solusi mengatasi perselisihan atau benturan antara rasa kradamangsa kita dengan rasa kradamangsa pihak lain. Dengan melepaskan rasa kradamangsa yang telah menjadi catatancatatan pengalaman hidup membuat kita tidak terbentur dengan pihak lain. Mawas diri merupakan kepribadian sejati ala Suryomentaraman, ialah teknik olah rasa untuk memilah rasa kradamangsa kita dengan rasa orang lain, menghayati rasa kradamangsa orang lain dan rasa sendiri, agar mencapai manusia tanpa ciri (Afif, 2020). Kepribadian mawas diri menuju manusia tanpa ciri akan menghantarkan kita menjadi pribadi yang bahagia di kemudian hari (Akhtar, 2018).

Beberapa ahli psikologi Indonesia mengatakan bahwa konsep kepribadian ala Suryomentaraman ini bersifat emik, hanya berlaku atau dialami orang Jawa saja (Prihartanti, 1999). Darmanto Jatman (Widyarini, 2008) juga mengatakan konsep kepribadian Suryomentaraman merupakan produk intelektual orang Jawa. Namun, ada beberapa ahli lainnya seperti Prawitasari (2006) dan juga Widyarini (2008) berpendapat bahwa konsep kepribadian Suryomentaraman bersifat etik, artinya berlaku dan dialami semua manusia di berbagai budaya. Hal ini berdasarkan praktik konseling yang dilakukan Widyarini (2008) dengan menerapkan konsep kepribadian Suryomentaraman ternyata berhasil menyembuhkan perilaku negatif yang diderita klien dari berbagai latar budaya yang berbeda. Bahkan Widyarini (2008) mengatakan bahwa konsep kepribadian Suryomentaraman ini bisa disejajarkan dengan teknik analisis transaksional dan teknik flow dari Csikszentmihslyi yang diterapkan dalam proses konseling. Tampak, secara praktis bahwa konsep kepribadian Suryomentaraman ini berlaku universal (etik), namun di satu sisi juga merupakan produk kekayaan intelektual manusia nusantara (Jawa) yakni Suryomentaraman.

\section{Nilai Budaya Batak Toba Membentuk Motivasi Berprestasi}

Setiap komunitas masyarakat memiliki nilai-nilai budaya yang khas dan menjadi prinsip/pedoman hidup masyarakat tersebut (Adisubroto, 1993; Schwartz \& Bardi, 2001; Matsumoto, 2008; Pramudito, 2017). Nilai-nilai budaya ini diwariskan dari generasi ke generasi (Adisubroto, 1993; Saliyo, 2012; Afiah, 2015; Valentina \& Martani, 2018; Etikawati et al., 2019). Dalam masyarakat Batak Toba memiliki sembilan 
nilai-nilai budaya sebagaimana ulasan Sumanjuntak (Valentina \& Martani, 2018). Kesembilan nilai budaya Batak Toba yang ditransmisikan dari generasi ke generasi ialah nilai kekerabatan, religi, hagabeon (keturunan), hasangapon (kemuliaan), hamoraon (kekayaan), patik dohot uhum (taat hukum), pengayoman (pelindung), dan marsisarian (saling mengerti, menghargai, dan membantu).

Kesembilan nilai budaya Batak Toba itu ditransmisikan orang tua kepada anakanaknya melalui pola asuh otoritatif (Irmawati, 2002). Berbeda dari pendapat Irmawati (2002), Simarmata et al (2012) memposisikan nilai-nilai budaya Batak Toba ditransmisikan kepada anak-anak melalui beragam bentuk pola asuh yang diterapkan orang tua. Nilai budaya hagabeon dan hasangapon ini diwariskan kepada anak melalui pola asuh demokratis, otoriter dan permisif, sedangkan nilai budaya hamoraon ini diwariskan melalui pola asuh otoriter dan permisif. Nilai-nilai budaya yang ditransmisikan kepada anak-anak Batak Toba ini kemudian mengkristal menjadi kepribadian individu Batak Toba. Dalam ulasan Carl Gustav Jung (Widaningrum, 2006), bahwa nilai-nilai budaya yang ditransmisikan kepada setiap generasi akan menjadi archetype (ketidaksadaran kolektif; original pattern; living ideas) bagi setiap individu di masa mendatang.

Tiga dari kesembilan nilai Batak Toba yang paling tampak membentuk archetype (pandangan hidup; kepribadian) individu ialah hasangapon, hagabeon, dan hamoraon (Valentina \& Martani, 2018). Pertama, nilai hasangapon ini mendorong setiap anak Batak Toba harus meraih kemuliaan dan kehormatan (Valentina \& Martani, 2018; Simarmata et al., 2012). Dalam konteks modern, nilai-nilai hasangapon ini mendorong setiap anak Batak Toba harus mengejar prestasi maksimal dalam dunia akademik (pendidikan) agar dapat memperoleh pekerjaan, pangkat, dan jabatan di kemudian hari, sehingga si anak dapat dihormati orang lain (Irmawati, 2007; Valentina \& Martani, 2018; Simarmata et al., 2012). Irmawati (2002, 2007) menduga bahwa nilai-nilai hasangapon ini menumbuhkan afiliasi, power, dan achievement selaras dengan konsep motivasi dari McClelland. Dugaan ini dapat diterima, sebab nilai-nilai budaya Batak Toba tampaknya membentuk motivasi berprestasi individu.

Kedua, nilai hagabeon ialah kehadiran keturunan (anak) dipersepsikan suku Batak Toba sebagai kekayaan berharga (Valentina \& Martani, 2018; Simbolon \& Siregar, 2014; Irmawati, 2007; Simarmata et al., 2012). Simbolon dan Siregar (2014) berpendapat bahwa orang Batak memandang keturunan sebagai pemberi harapan hidup, kebahagiaan, dan kesejahteraan. Sebab, dengan adanya keturunan maka martabat keluarga akan terangkat ketika si anak berhasil dalam dunia akademik dan berhasil memperoleh pekerjaan (Irmawati, 2007; Valentina \& Martani, 2018). Oleh karena itu, hadirnya keturunan dipandang sebagai harta paling berharga bagi suku Batak Toba. Dalam ulasan Irmawati (2007) bahwa realisasi nilai hagabeon ini akan mendorong si anak suku Batak Toba memenuhi tuntutan nilai hasangapon. Artinya, agar mencapai kehormatan (hasangapon), maka setiap individu (yang telah berkeluarga) harus mempunyai anak (hagabeon). Kehadiran anak dipandang oleh suku Batak Toba dapat mendatangkan kehormatan bagi si anak sendiri dan juga keluarganya.

Ketiga, nilai hamoraon ialah pemenuhan kekayaan (Simarmata et al., 2012; Irmawati, 2007; Valentina \& Martani, 2018). Kekayaan dalam pandangan suku Batak Toba bersifat materi dan non-materi, hal ini diperoleh melalui usaha dan kerja keras (Simarmata et al., 2012). Kekayaan materi ini misalnya uang dan harta benda lainnya, sedangkan kekayaan non-materi ialah pangkat/jabatan dan prestasi akademik. Dalam ulasan Irmawati (2007) bahwa nilai hasangapon (kehormatan) individu dapat terealisasi apabila telah memenuhi nilai-nilai hagabeon dan hamoraon. Oleh karena itu, suku Batak Toba menekankan harus punya anak (keturunan) agar mereka dapat meraih kekayaan (hamoraon) sehingga dihormati/ dihargai orang lain (hasangapon). 
Irmawati (2007) menunjukkan bahwa nilai-nilai hasangapon, hagabeon, dan hasangapon ini merupakan terminal values yang harus dicapai karena nilai-nilai tersebut merupakan tujuan hidup suku Batak Toba. Untuk memenuhi ketiga nilai inti tersebut, maka diperlukan instrumental values yakni religi, hamajuon, patik dohot uhum (patut pada hukum), dan pengayoman. Instrumental values ini sebagai konduksi untuk memenuhi ketiga nilai inti (terminal values) yakni hasangapon, hagabeon, dan hamoraon. Ketiga nilai ini saling berkaitan antara satu dengan lainnya (Simarmata et al., 2012), menjadi nilai-nilai filsafat hidup (archetype) suku Batak Toba sehingga melahirkan kepribadian motivasi berprestasi di kemudian hari (Irmawati, 2007).

\section{Kepribadian Toleransi dalam Budaya Pela- Gandong di Maluku}

Pela dan gandong merupakan produk intelektual sekaligus modal sosial yang dimiliki orang Maluku (Sopamena, 2020). Pela berarti ikatan perjanjian antara dua atau lebih negeri (negeri: desa) dalam satu daratan pulau atau lintas pulau di provinsi Maluku (Ralahallo, 2009). Ikatan ini melahirkan relasi positif antar-individu dari dua atau lebih negeri di Maluku. Asal-usul makna pela berarti "habis" (Sopamena, 2020), diambil dari kasus pertikaian yang pernah dialami dua/lebih negeri di masa lampau sehingga melahirkan sebuah perjanjian yang bermakna bahwa pertikaian itu sudah selesai alias habis (pela).

Uniknya, pertikaian yang terjadi di masa lampau melahirkan ikatan kekerabatan yang kuat di kemudian hari. Padahal, kalau dicermati lebih dalam biasanya kasus-kasus pertikaian antara dua negeri akan melahirkan motif eksploitatif, namun motif ini tidak muncul di Maluku, malah sebaliknya melahirkan relasi kekerabatan (pela) yang kuat di kemudian hari. Mengapa hal ini bisa terjadi? Meminjam ulasan Carl Gustav Jung, perumus psikologi analitis, mengatakan bahwa setiap individu dalam komunitas tertentu menyimpan "ketidaksadaran kolektif" (archetype) yang mendorong individu mengaplikasikan relasi dan interrelasi positif di dalam komunitas (Widaningrum, 2006). Relasi dan inter-relasi ini memiliki dampak transformatif bagi setiap komunitas. Oleh karena itu, kemungkinan lahirnya ikatan pela berangkat dari archetype setiap individu di Maluku. Dalam pandangan orang Maluku menyimpan archetype bahwa kediri-an mereka berasal dari satu ras yang sama sehingga pertikaian tidak boleh terjadi di Maluku (Manuputty et al., 2014; Tiwery, 2015; Bartels, 2017). Archetype orang Maluku ini sangat berkorelasi dengan makna gandong yang berarti bahwa ikatan persaudaraan lintas-negeri (kampung) didasarkan oleh faktor geneologis di masa lampau (Ralahallo, 2009).

Sejarawan Maluku, Tawainella mengatakan bahwa ikatan gandong lebih dulu ada dibanding ikatan pela (Sopamena, 2020). Hal ini karena ikatan pela yang lahir belakangan berasal dari archetype yang di dalamnya menyimpan makna gandong sebelumnya. Ikatan pela yang lahir atas dasar gandong ini biasa disebut dengan istilah "pela gandong", yakni suatu hubungan sakral antara dua/lebih negeri sehingga dilarang keras bertikai antara satu dengan lainnya. Bahkan, kedua negeri di larang menikahi saudaranya sendiri, karena ada hubungan "darah" (gandong) yang kuat antar-negeri tersebut. Hubungan sakral itu menerobos unsur-unsur perbedaan agama antara dua negeri yang sedang ber-pela gandong. Misalnya, negeri Siri-Sori Islam (muslim) berpela gandong dengan negeri Haria (kristiani) di pulau Saparua, kedua negeri ini tidak pernah bertikai sampai detik ini.

Konsep relasi antar-individu, biasanya berasal dari nilai-nilai budaya yang diturunkan dari generasi ke generasi (Adisubroto, 1993; Saliyo, 2012; Afiah, 2015; Etikawati et al., 2019; Nashori et al., 2020). Di Maluku, konsep relasi itu berasal dari nilai-nilai budaya yakni pela dan gandong. Nilai-nilai pela-gandong ditransmisikan orang tua kepada anak-anaknya melalui berbagai cara, misalnya lewat nyanyian kapata (cerita rakyat masa silam) yang ditampilkan pada saat upacara adat, atau 
lewat cerita langsung kepada anak-anak. Nilai-nilai pela-gandong yang ditransmisikan itu berdampak pada pembentukan kepribadian individu saat berhadapan dengan seseorang yang ber-pela gandong dengannya. Salah-satu bentuk kepribadian yang terselip dalam budaya pela-gandong ialah toleransi (Ralahallo, 2009), yang begitu tampak dalam hubungan antar-individu dari dua/lebih negeri di Maluku.

\section{Karakteristik Kepribadian Nusantara}

Sebetulnya, masih ada banyak nilai-nilai budaya yang sangat kuat membentuk kepribadian nusantara, namun sejauh ini masih minim penelitian yang dilakukan para ahli psikologi Indonesia mengenai hal tersebut. Karena keterbatasan sumber penelitian, maka dalam artikel ini hanya dipaparkan tiga kepribadian nusantara yakni kepribadian ala Suryomentaraman (Jawa), kepribadian motivasi berprestasi ala suku Batak Toba, dan kepribadian toleransi dalam budaya pela-gandong di Maluku.

Berdasarkan ulasan di atas, tampak bahwa karakteristik kepribadian nusantara ialah pertama mawas diri sebagai teknik olah rasa membentuk kebahagiaan subjektif ala Suryomentaraman. Kedua, kepribadian nusantara memiliki karakteristik motivasi berprestasi sebagaimana terdapat dalam nilai-nilai budaya Batak Toba. Terakhir, ketiga yakni karakterstik kepribadian nusantara ialah toleransi dalam konsep pelagandong di Maluku.

\section{Relevansi Kepribadian Nusantara Mengatasi Perilaku Negatif}

Sejumlah karakteristik kepribadian nusantara itu cukup relevan mengatasi perilaku negatif yang belakangan muncul di tengah-tengah masyarakat. Hal ini terkonfirmasi dari beberapa studi terkait topik karakteristik kepribadian nusantara tersebut. Misalnya, studi pustaka yang dilakukan Akhtar (2018) mengatakan bahwa salah-satu konsep kebahagiaan orang Jawa terdapat dalam ajaran kawruh jiwa Ki Ageng Suryomentaraman. Tingkat kebahagiaan dapat mengatasi masalah kemalasan di tempat kerja, mendorong individu berpartisipasi dalam organisasi masyarakat, mengatasi masalah keluarga (cerai), dan meningkatkan performa kerja (Diener \& Chan, 2011). Selain itu, kebahagiaan juga dapat mengatasi depresi, stres dan kecemasan (Khayeri et al., 2016). Artinya, tingkat kebahagiaan mendorong terciptanya suasana kehidupan yang harmonis. Hal ini berarti bahwa karakterstik kepribadian nusantara ala Suryomentaraman yang menekankan tingkat kebahagiaan sangat relevan mengatasi masalah perilaku negatif yang muncul di tengah-tengah masyarakat.

Selain konsep kebahagiaan yang merupakan karakteristik kepribadian nusantara orang Jawa, terdapat juga karakteristik kepribadian nusantara suku Batak. Sebagaimana telaah pustaka di atas bahwa karakteristik kepribadian nusantara yang dimiliki suku Batak ialah motivasi berprestasi. Sejumlah penelitian mengkonfirmasi bahwa motivasi berprestasi dapat mengatasi masalah ketidaksejahteraan peserta didik di sekolah (Boncquet et al., 2020). Lanjut Boncquet et al (2020) bahwa motivasi berprestasi dapat meningkatkan iklim kesejahteraan dan peningkatan kecerdasan peserta didik di sekolah. Selain itu, motivasi berprestasi juga dapat mengatasi masalah burnout yang kerap terjadi di dunia pendidikan (Moghadam et al., 2020). Bahkan, motivasi juga dapat meningkatkan performansi kerja individu (Kiuru et al., 2020). Karena motivasi dapat meningkatkan nusansa hidup yang produktif, maka nilai-nilai motivasi yang menjadi spirit kepribadian nusantara suku Batak ini sangat relevan mengatasi perilaku negatif di tengah-tengah masyarakat.

Konsep toleransi dalam karakteristik kepribadian nusantara ala orang Maluku juga sangat relevan mengatasi masalah konflik sosial yang kerap terjadi di tengahtengah masyarakat. Sebagaimana ulasan sejumlah ahli seperti Latif (2019) dan Madjid (2019) mengatakan bahwa toleransi dapat mengatasi masalah konflik sosial akibat perbedaan pandangan. Karena di dalam toleransi terdapat spirit titik-temu antara dua/lebih komunitas yang berbeda 
pandangan untuk saling bekerjsama menuju cita-cita kemajuan (Latif, 2019). Toleransi juga dapat meningkatkan kebahagiaan di tengah-tengah masyarakat (Pagès-El Karoui, 2021). Bahkan dalam ulasan Raihani (2014) yang meneliti tingkat toleransi pasca konflik di Palangkaraya menunjukkan bahwa toleransi dapat meningkatkan kualitas hidup masyarakat ke arah yang lebih baik dan positif. Hal ini berarti bahwa konsep toleransi yang dimiliki orang Maluku sangat relevan mengatasi perilaku negatif seperti kekerasan, konflik sosial, dan sejenisnya akibat perbedaan pandangan.

Berdasarkan ulasan tersebut, maka dapat dikatakan bahwa karakteristik kepribadian nusantara, baik dari orang Jawa, Batak, maupun Maluku sangat relevan mengatasi perilaku negatif yang kerap muncul di tengah-tengah masyarakat. Oleh karena itu, karakteristik kepribadian nusantara dapat dikatakan sebagai sumber solusi mengatasi problem sosial di kemudian hari.

\section{Kesimpulan}

Berdasarkan kajian di atas maka terdapat sejumlah karakteristik kepribadian nusantara ialah kebahagiaan, motivasi, dan toleransi. Karakteristik kepribadian nusantara ini dapat menjadi solusi untuk mengatasi masalah perilaku negatif yang kerap muncul di tengah-tengah masyarakat. Meskipun demikian, kepribadian nusantara dalam kajian ini masih jauh dari kata "sempurna". Hal ini karena masih minim studi-studi psikologi terkait upaya menggali nilai-nilai budaya nusantara dan mengkonstruknya menjadi kepribadian individu ala nusantara.

Oleh karena itu, saran bagi para peneliti selanjutnya (terutama ahli psikologi) ialah untuk menggali nilai-nilai budaya nusantara yang memiliki korelasi membentuk kepribadian individu. Selain itu, agar kepribadian nusantara ini berlaku universal khusus dalam teritorial Indonesia, maka perlu dilakukan penelitian psikologi lintas budaya antar setiap daerah di Indonesia.

\section{Ucapan Terima Kasih}

Terima kasih kepada pimpinan dan seluruh dosen IAIN Ambon yang telah memberi akses dan kemudahan dalam penelusuran sumber-sumber penelitian psikologi. Selain itu, penulis juga mengucapkan terima kasih kepada reviewer yang sudah memberi saran dan komentar sehingga artikel ini dapat selesai tepat waktu.[]

\section{Daftar Pustaka}

Adisubroto, D. (1993). Nilai: Sifat dan fungsinya. Buletin Psikologi, 1(2), 28-33. https://doi.org/10.22146/BPSI.13163

Afiah, N. (2015). Kepribadian dan agresivitas dalam berbagai budaya. Buletin Psikologi, 23(1), 13-21. https:// jurnal.ugm.ac.id/buletinpsikologi/ article/view/10573

Afif, A. (2020). Psikologi Suryomentaraman. Yogyakarta: IRciSoD. https://books. google. co.id/books/about/Psikologi_ Suryomentaraman.html?id=qHDVDw AAQBAJ\&redir_esc=y

Akhtar, H. (2018). Perspektif kultural untuk pengembangan pengukuran kebahagiaan orang Jawa. Buletin Psikologi, 26(1), 54-63. https://doi.org/ 10.22146/buletinpsikologi.30895

Andayani, B. (2004). Tinjauan pendekatan ekologi tentang perilaku pengasuhan orang tua. Buletin Psikologi, 12(1), 4460.

Bartels, D. (2017). Di bawah naungan gunung Nunusaku: Muslim-kristen hidup berdampingan di Maluku Tengah. Jakarta: PT Gramedia.

Binder, A., Denkinger, J., El-Sount, C. R., Windthorst, P., Engelhardt, M., Ringwald, J., Stuber, F., Nikendei, C., Kindermann, D., Komandur, P., Zipfel, S., \& Junne, F. (2020). Psychological burden, stressors and resources of social workers working with women and children who suffered extreme violence by the 'Islamic state': A mixed 
method study. Journal of Psychosomatic Research, 132. https://doi.org/10.1016/ J.JPSYCHORES.2020.109959

Boncquet, M., Soenens, B., Verschueren, K., Lavrijsen, J., Flamant, N., \& Vansteenkiste, M. (2020). Killing two birds with one stone: The role of motivational resources in predicting changes in achivement and school well-being beyond intelligence. Contemporary Educational Psychology, 63. https://doi.org/10.1016/j.cedpsych. 2020.101905

Caruso, R., \& Schneider, F. (2011). The socioeconomic determinants of terrorism and political violence in Western Europe (1994-2007). European Journal of Political Economy, 27(1), 537-549. ht t p s://doi.org/10.1016/ J.EJPOLECO.2011.02.003

Diener, E., \& Chan, M. Y. (2011). Happy people live longer: Subjective wellbeing contributes to health and longevity. Applied Psychology: Health and Well-Being, 3(1), 1-43. https:// d o i . or g/10.1111/j. 1758 0854.2010.01045.x

Ellis, L. (2017). Religious variations in fundamentalism in Malaysia and the United States: Possible relevance to religiously motivated violence. Personality and Individual Differences, 107, 23-27. https://doi.org/10.1016/ J.PAID.2016.11.012

Etikawati, A. I., Siregar, J. R., Widjaja, H., \& Jatnika, R. (2019). Mengembangkan konsep dan pengukuran pengasuhan dalam perspektif kontekstual budaya. Buletin Psikologi, 27(1), 1-14. https:// jurnal.ugm.ac.id/buletinpsikologi/ article/view/41079

ICW. (2020). Evaluasi satu tahun Komisi Pemberantasan Korupsi (KPK). https:// antikorupsi.org/id/article/evaluasisatu-tahun-komisi-pemberantasankorupsi-2020

Fink, A. (2020). Conducting research literature reviews: From the internet to paper.
London: Sage Publication. https:// www.amazon.com/ConductingResearch-Literature-Reviews-4/dp/ 1452259496

Irmawati. (2002). Motivasi berprestasi dan pola pengasuhan pada suku bangsa Batak Toba di Desa Parparean II dan suku bangsa Melayu di Desa Bogak (studi etnopsiikologi) [Universitas Indonesia]. http://lib.ui.ac.id/file?file=pdf/Abstrak20342483.pdf

Irmawati. (2007). Keberhasilan suku Batak Toba (tinjauan psikologi ulayat). 1-9. http:// repository.usu.ac.id/bitstream/handle/ 123456789/16042/08E00550.pdf? sequence $=3 \&$ isAllowed $=\mathrm{y}$

Khattab, N., Miaari, S., Mohamed-Ali, M., \& Abu-Rabia-Queder, S. (2018). Muslim women in the Canadian labor market: Between ethnic exclusion and religious discrimination. Research in Social Stratification and Mobility, 61, 5264. https://doi.org/10.1016/J.RSSM. 2018.11.006

Khayeri, F., Rabiei, L., Shamsalinia, A., \& Masoudi, R. (2016). Effect of fordyce happiness model on depression, stress, anxiety, and fatigue in patients with multiple sclerosis. Complementary Therapies in CLinical Practice. https:// doi.org/10.1016/j.ctcp.2016.09.009

Kiuru, N., Spinath, B., Clem, A.-L., Eklund, K., Ahonen, T., \& Hirvonen, R. (2020). The dynamics of motivation, emotion, and task performance in simulated achievement situations. Learning and Individual Differences, 80. https:// doi.org/10.1016/j.lindif.2020.101873

Komnas HAM. (2019). Diskriminasi Ras dan Etnis Berpotensi Membesar. https:// www.komnasham.go.id/index.php/ news/2019/9/14/1155/komnas-hamdiskriminasi-ras-dan-etnis-berpotensimembesar.html

Kusumawardani, A., \& Faturochman. (2004). Nasionalisme. Buletin Psikologi, 12(2), 61-72. https://jurnal.ugm.ac.id/ buletinpsikologi/article/view/7469 
Latif, Y. (2019). Negara Paripurna: Historitas, Rasionalitas, Aktualitas Pancasila (Cetakan ketujuh). Jakarta: PT Gramedia.

Li, W., Yigitcanlar, T., Erol, I., \& Liu, A. (2021). Motivations, barriers and risks of smart home adoption: From systematic literature review to conceptual framework. Energy Research $\mathcal{E}$ Social Science, 80. https://doi.org/ 10.1016/j.erss.2021.102211

Lubis, M. (2012). Manusia Indonesia. Jakarta: Yayasan Pustaka Obor Indonesia.

Madjid, N. (2019). Islam Doktrin dan Peradaban: Sebuah Telaah Kritis tentang Keimanan, Kemanusiaan, dan Kemodernan. Jakarta: PT Gramedia.

Manuputty, J., Salampessy, Z., Ali-Fauzi, I., \& Rafsadi, I. (2014). Carita orang basudara: Kisah-kisah perdamaian dari Maluku. Lembaga Antar Iman Maluku. https://www.neliti.com/publications/ $818 /$ carita-orang-basudara-kisahkisah-perdamaian-dari-maluku

Matsumoto, D. (2008). Pengantar psikologi lintas budaya. Yogyakarta: Pustaka Pelajar.

Moghadam, M. T., Abbasi, E., \& Khoshnodifar, Z. (2020). Students' academic burnout in Iranian agricultural higher education system: The mediating role of achievement motivation. Heliyon, 6. https://doi.org/ 10.1016/j.heliyon.2020.e04960

Muluk, H. (2008). Psikologi korupsi. Seputar Indonesia, 1.

Nainggolan, P. P. (2014). Aktivitas internasional gerakan separatisme Papua. Kajian, 19 (3), 181-199. https:// doi.org/10.22212/KAJIAN.V19I3.555

Nashori, F., Nurdin, M. N. H., Herawati, N., Diana, R. R., \& Masturah, A. N. (2020). Keterikatan interpersonal pada beberapa etnis besar di Indonesia. Jurnal Psikologi Sosial, 18, 53-63. https:/ /www.researchgate.net/publication/ 349636134_Keterikatan_Interpersonal_
pada_Beberapa_Etnis_Besar_di_ Indonesia

Nyarko, F., Peltonen, K., Kangaslampi, S., \& Punamäki-Gitai, R. L. (2020). How stressful life events and violence are related to mental health: the protective role of social relations in African context. Heliyon, 6(8). https://doi.org/ 10.1016/J.HELIYON.2020.E04629

Pagès-El Karoui, D. (2021). Ambivalent cosmopolitanism from above in Dubai: Forging landscapes of tolerance and happiness in a global city. City: Analysis of Urban Change, Theory, Action. https:/ /doi.org/10.1080/13604813. 2021. 1885918

Pramudito, A. A. (2017). Merenda cinta melintas budaya hingga senja tiba (studi literatur tentang perkawinan antar-budaya). Buletin Psikologi, 25(2), 76 - 88. https://jurnal.ugm.ac.id/ buletinpsikologi/article/view/27233

Prawitasari, J. E. (2006). Psikologi Nusantara: Kesanakah kita menuju? Buletin Psikologi, 14(1). https://doi.org/ 10.22146/bpsi.7484

Prihartanti, N. (1999). Pengembangan kualitas kepribadian melalui olah rasa. Anima, 15, 66-75.http:// a $\mathrm{n}$ i m a . u b a y a c . id/ind ex . php?menu=articles\&eid $=1350456866 \&$ actsub=yes\&eidsub=1357889888

Prihartanti, N., Suryabrata, S., Prawitasari, J. E., \& Wibisana, K. (2003). Kualitas kepribadian ditinjau dari konsep Suryomentaram dalam perspektif psikologi. Anima2, 18, 229-247. http:// anima.ubaya.ac.id/index.php? menu= articles\&eid $=1350456899 \&$ actsub $=$ yes\& eidsub=1359082440

Raihani. (2014). Creating a culture of religious tolerance in an Indonesian school. South East Asia Research, 22(4), 541-560. https://doi.org/10.5367/ sear.2014.0234

Ralahallo, R. N. (2009). Kultur damai berbasis tradisi pela dalam perspektif 
psikologi sosial. Jurnal Psikologi, 36(2), 177 - 188. https://doi.org/10.22146/ JPSI.7894

Rowatt, W. C., \& Al-Kire, R. L. (2021). Dimensions of religiousness and their connection to racial, ethnic, and atheist prejudices. Current Opinion in Psychology, 40, 86-91. https://doi.org/ 10.1016/J.COPSYC.2020.08.022

Sairin, S. (2000). Disintegrasi sosial: Sebuah tinjauan budaya. Humaniora, 12(3), 306-312. https://doi.org/10.22146/ JH.703

Saliyo. (2012). Konsep diri dalam budaya Jawa. Buletin Psikologi, 20(1-2), 26-35. ht t p s://jurnal.ugm.ac.id/ buletinpsikologi/article/view/11946

Schwartz, S. H., \& Bardi, A. (2001). Value hierarchies across cultures: Taking a similarities perspective. Journal of Cross-Cultural Psychology, 32(3), 268290. https://doi.org/10.1177/ 0022022101032003002

Simarmata, N., Widarnandana, I. G. D., Pratama, A. H., \& Putra, I. P. G. D. P. (2012). Persepsi terhadap nilai budaya Batak (hamoraon, hagabeon, hasangapon) dan pola asuh pada perantau Batak di Bali. Tantangan Pengembangan Psikologi Indonesia, 7281.

Simbolon, C. J., \& Siregar, R. H. (2014). Nilai hagabeondan upaya memperoleh keturunan pada pasangan suku Batak Toba yang infertil. Psikologia, 9, 25-31. https://adoc.pub/nilai-hagabeon-danupaya-memperoleh-keturunan-padapasangan-.html

Sobandi, K. R. (2011). Separatisme di Asia Tenggara: Antara penguasa dan gerakan nasionalis kelompok minoritas. Jurnal Kajian Wilayah, 2(1), 35-55. https://doi.org/10.14203/ JKW.V2I1.320

Soeparno, K., \& Sandra, L. (2011). Social psychology: The passion of psychology. Buletin Psikologi, 19(1), 1628.
Sopamena, C. A. (2020). Filosofi pela-gandong: Katup penyelamat masyarakat Maluku. Yogyakarta: Deepublish. https:// penerbitbukudee publish.com/shop/ buku-filosofi-pela-gandong-katuppenyelamat-masyarakat-maluku/

Stanger, N. R. G. (2011). Moving “eco" back into socio-ecological models: A proposal to reorient ecological literacy into human development models and school systems. Human Ecology Forum, 18(2), 167-173.

Steel, Z., Chey, T., Silove, D., Marnane, C., Bryant, R. A., \& van Ommeren, M. (2009). Association of torture and other potentially traumatic events with mental health outcomes among populations exposed to mass conflict and displacement: A systematic review and meta-analysis. America Medical Association, 302(5), 537-549.

Subandi. (1995). Perkembangan kehidupan beragama. Buletin Psikologi, 3, 11-18. h t t p s : / / jurna 1.ug m . a c.id/ buletinpsikologi/article/view/13379

Sumanto. (2006). Kajian psikologis kebermaknaan hidup. Buletin Psikologi, 14(2), 115-135. https://doi.org/ 10.22146/BPSI.7490

Sumanto. (2011). Kesejahteraan subyektif menurut Ki Ageng Suryomentaraman (KASM) dalam perspektif psikologi kontemporer. Buletin Psikologi, 19(1), 29-37. https://jurnal.ugm.ac.id/ buletinpsikologi/article/view/11545

Susanto, E. (2009). Memahami Korupsi dari perspektif perilaku organisasi: Mengapa seseorang terjebak dalam perilaku korup? JKAP (Jurnal Kebijakan Dan Administrasi Publik), 13(1), 18-30. https://doi.org/10.22146/JKAP.8178 